\title{
CONVERSIÓN DE LA VILLA DE ALICANTE EN CIUDAD
}

\author{
Juan-Manuel del Estal \\ Universidad de Alicante
}

Al conmemorarse este año el $V$ Centenario de la elevación de la villa de Alicante a ciudad, por real decreto de Fernando $V$ de Castilla y ll de Aragón, despachado en Córdoba a 26 de julio de 1490, deseamos dedicar un recuerdo a aquella venturosa efeméride en las líneas que siguen.

Nos parece muy indicado aprovechar esta circunstancia especial para publicar el texto latino original, tomándolo por primera vez del pergamino auténtico, expedido por la propia cancillería real de Córdoba, en la fecha indicada (1), acompañándolo de un breve comentario histórico, previo, y de su versión castellana, propia, al final.

\section{COMENTARIO HISTORICO}

Las circunstancias singulares que proporcionaron al viejo nucleo urbano cartaginés de Akra Leuka o colonia romana de Lucentum o ciudad musulmana de Al-Lakant, el feliz tránsito de villa a ciudad, son los motivos que aduce precisamente Fernando el Católico para decorarla con tal título honorífico. Motivos éstos justamente que nos proponemos comentar a continuación.

Tan venturoso suceso histórico iba a tener lugar a los casi dos siglos y medio de la conquista y repoblación castellana de la ciudad muslim de Alicante (1247-1490) por el infante de Castilla, D. Alfonso el Sabio, y a los casi 
también doscientos años de su conquista aragonesa y repoblación valenciana (1296-1490) por el rey Jaime II el Justo, quien la incorporó primero a su corona, con todo el reino de Murcia (1296-1304), y luego al reino de Valencia (1304 y 1308) de manera formal y definitiva hasta la fecha (2).

Entre los motivos que esgrimió el rey $D$. Fernando $V$ de Castilla y II de Aragón, para elevar la villa de Alicante al noble rango de ciudad, enumera en primer término los manifiestos logros alcanzados en áreas del comercio, de la propia agricultura, de la artesanía e industria en grado notable, cabe un desarrollo económico creciente y un encomiable renacimiento urbano muy singular.

En dos provisiones reales sucesivas, a muy escasa distancia entre sí (19 y 26 de julio del 1490) presenta el Rey Católico las razones concretas que le han inducido a dispensar a la villa de Alicante peculiares favores fiscales, como la autorización del cobro del impuesto de la sisa sobre las mercancías que entran y salen de su puerto, bajo el concepto de derechos del muelle: dret del mollatge y otras franquicias reales de claro favor para el concejo alicantino (ESTAL, Alicante de villa a ciudad, 1990, núms. 180 y 181).

Por el primer privilegio citado (19 julio) se proponía Fernando el Católico confirmar, a petición del consell alicantino, dos concesiones de su augusto padre, Juan II de Aragón, concernientes al cobro de ciertos derechos de muelle por el municipio de Alicante, sobre los productos que entraran y salieran de su puerto. Databan tales privilegios del 8 diciembre de 1475, el primero, y el segundo del 18 marzo de 1476 (ibid.). Por tratarse de una villa de realengo no pudo confirmarle los derechos de muelle solicitados, pero sí el cobro del impuesto de la sisa sobre las mercancias que entrasen y saliesen del mismo.

Se le obligaba no obstante a dedicar los ingresos percibidos por tal impuesto comunal en un cuarto del mismo al mantenimiento y conservación del castillo: «in fabricam arcis sive castelli» (ibid. $n^{\circ} 180$ ) y el resto, tres cuartas partes, a las obras del puerto (ibid.).

Al no explicitarse en la segunda provisión real citada (18.3.1476) la dedicación de un cuarto del montante recaudado por el dret de mollatge, a razón de tres dineros por libra del valor de las mercancias en tránsito, para sostenimiento y conservación del castillo alicantino, quiso el rey D. Fernando el Católico corregir tal omisión.

Subsanar dicho silencio fue el cometido primario de su primera provisión ya citada (19 julio 1490), disponiendo que el consell alicantino podía libremente imponer en adelante «tantas sisas sive impositiones», cuantas acostumbra im- 


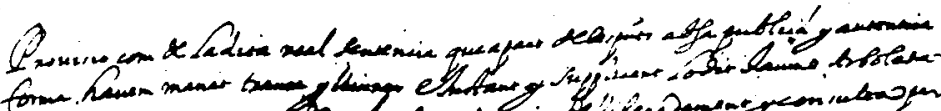

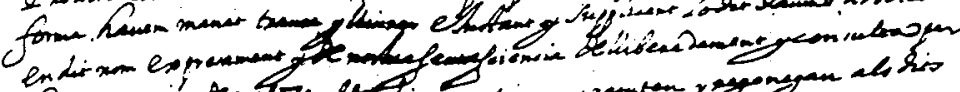

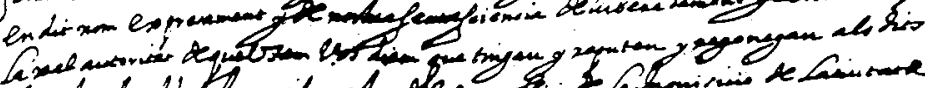

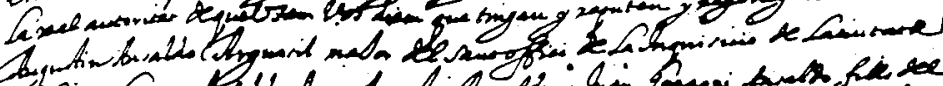

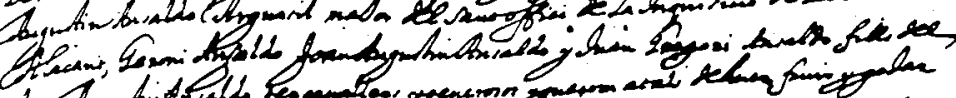

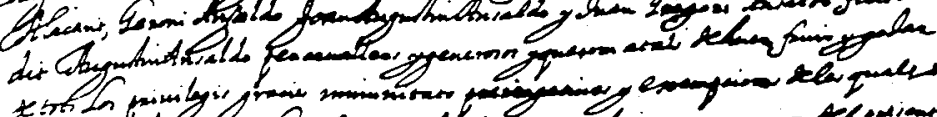

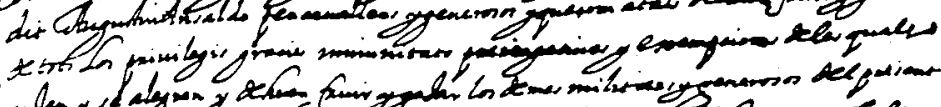

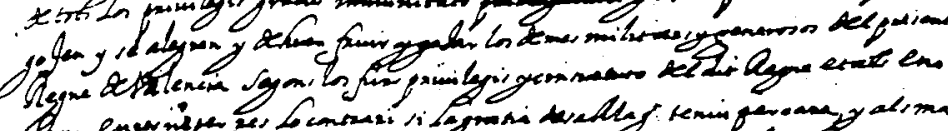

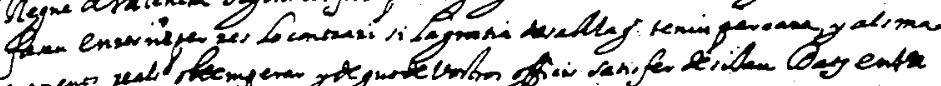

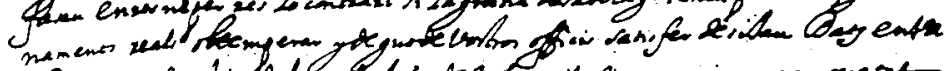

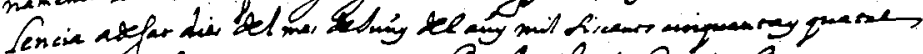
prontricitaing

Selinen. Ax

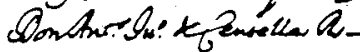

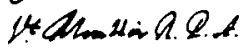

Bbidars

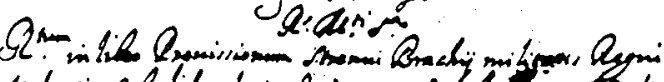

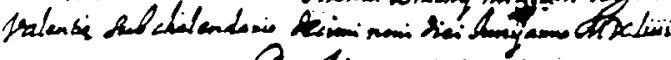
Andlay ans sams: $\longrightarrow$

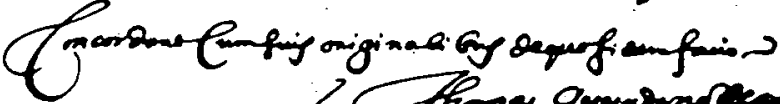

Se halla tambien

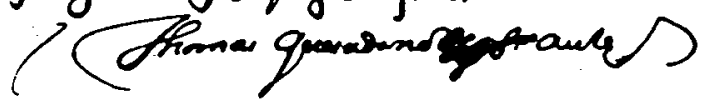

regurado, encl

perion.

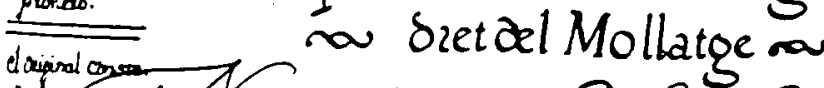

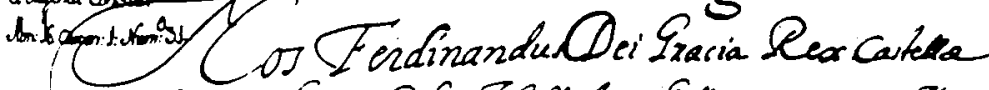

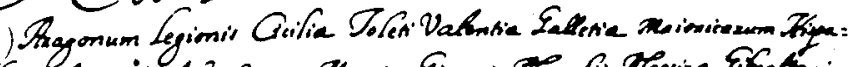

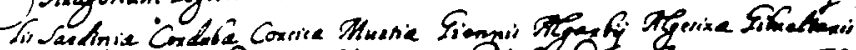

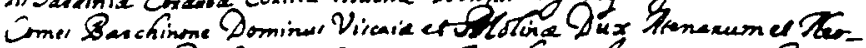

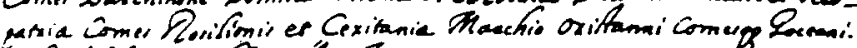

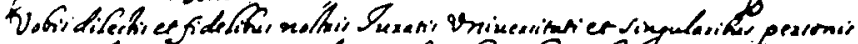

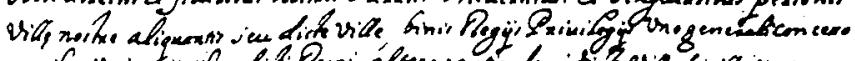

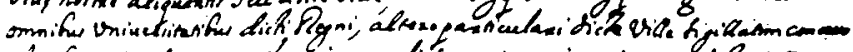

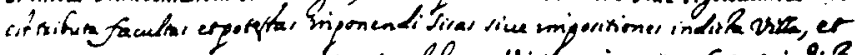

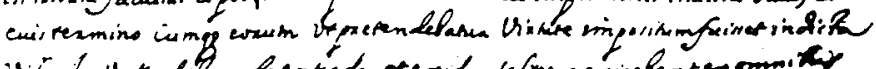

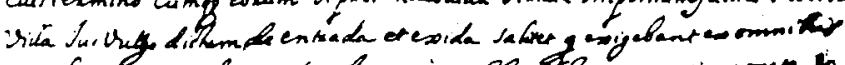

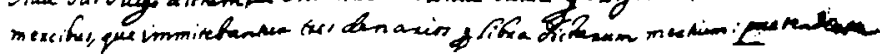

Fernando II el Católico concede el cobro de la sisa a la villa de Alicante (19.7.1479) en los derechos arancelarios del muelle (dret de mollatge). 
poner la ciudad de Valencia (ibid.). Y con referencia al destino de la cuarta parte de los ingresos por dret de mollatge del puerto alicantino a la conservación y mantenimiento del castillo, dispuso el monarca que "quia dictum castrum tutela et defensio magna est dicte ville et eius conservatio concernit servitium nostrum et beneficium dicte ville» (ESTAL, ibid. $n^{\circ} 180$ ), que se destinara a tal fin un cuarto de la suma recaudada y el resto a la conservación y mantenimiento del puerto y de su muelle, además de los materiales y máquinas de guerra necesarias para su defensa.

Y a fe que fueron dichos censos tributarios, concedidos por el Rey Católico al cónsell alicantino, de gran beneficio para la villa, incidiendo muy positivamente en la promoción de una mayor actividad comercial y creciente prosperidad socio-económica de la misma.

Pero el testimonio documental más elocuente del alto nivel económico alcanzado por la villa de Alicante en el último tercio del siglo XV, es la solemne provisión real de $\mathrm{D}$. Fernando el Católico, por la que, en la fecha indicada de 26 de julio del año 1490, le otorgó el honroso título de ciudad (Estal, ib., $\left.n^{\circ} 181\right)$.

Recordemos los motivos que indujeron a dicho monarca a tan expléndida resolución. «Y de aquí, nos dice, que considerando los muchos y memorables servicios, dignos de todo encomio, prestados por la villa de Alicante a nuestros predecesores los reyes de Aragón y de Valencia y a nos mismo, con singular afecto y excelente devoción, disponiendo de un poderoso colectivo de activos mercaderes, laboriosos campesinos, numerosos artesanos e industriales y gran número de hombres de armas de a caballo y de a pie, que la defienden a ultranza y la gobiernan bien, hemos decidido honrarla con el noble título de ciudad» (ibid., $\mathrm{n}^{\circ} 182$, traducción del autor).

Por cuanto cabe colegir claramente que la concesión del título de ciudad a la villa de Alicante, era en la mente del monarca un reconocimiento explícito en primer lugar de los cuantiosos méritos conseguidos e incomparables servicios prestados a la corona, dentro del marco administrativo del reino de Valencia y Gobernación General de Orihuela, de cuya frontera meridional era la llave y puerta, frente al reino de Granada, con su excelente puerto natural y no menos importante y estratégico castillo.

Condiciones éstas tan singulares de su ensenada natural e inespugnable castillo, que hace de sus moradores hombres sobremanera valerosos en tierra y en la mar, hasta el punto de no precisar de brazos extraños para su defensa y victoria segura sobre sus eventuales enemigos: «Villa Aliquantis, dice, 
nulla deo duce aliena ope indiget ad bene et polítice vincendump (ibid., $\mathrm{n}^{\circ}$ 181).

Dispone además la villa de Alicante, prosigue el monarca, de hombres hábiles en el comercio, en la explotación de la tierra, en la artesanía y en la industria, así como de hombres capacitados para gobernarla con acierto y defenderla con valor sin igual (ibid.).

Méritos sin duda éstos referidos más que suficientes para inducir al monarca a decorarla con el honroso título de ciudad. $Y$ tal fue la respuesta otorgada a los dos síndicos comunales enviados por el consell de Alicante a la presencia de D. Fernando para recabar de su comprensión tal intitulación. Eran dichos legados, el caballero D. Jaime Pascasio y el vecino alicantino D. Juan Torro. Y como ya hemos apuntado, el cometido asignado a tal embajada fue coronado enteramente por el éxito. Arrancando al monarca el decreto real por el que se otorgaba oficialmente el título de ciudad en estos términos:

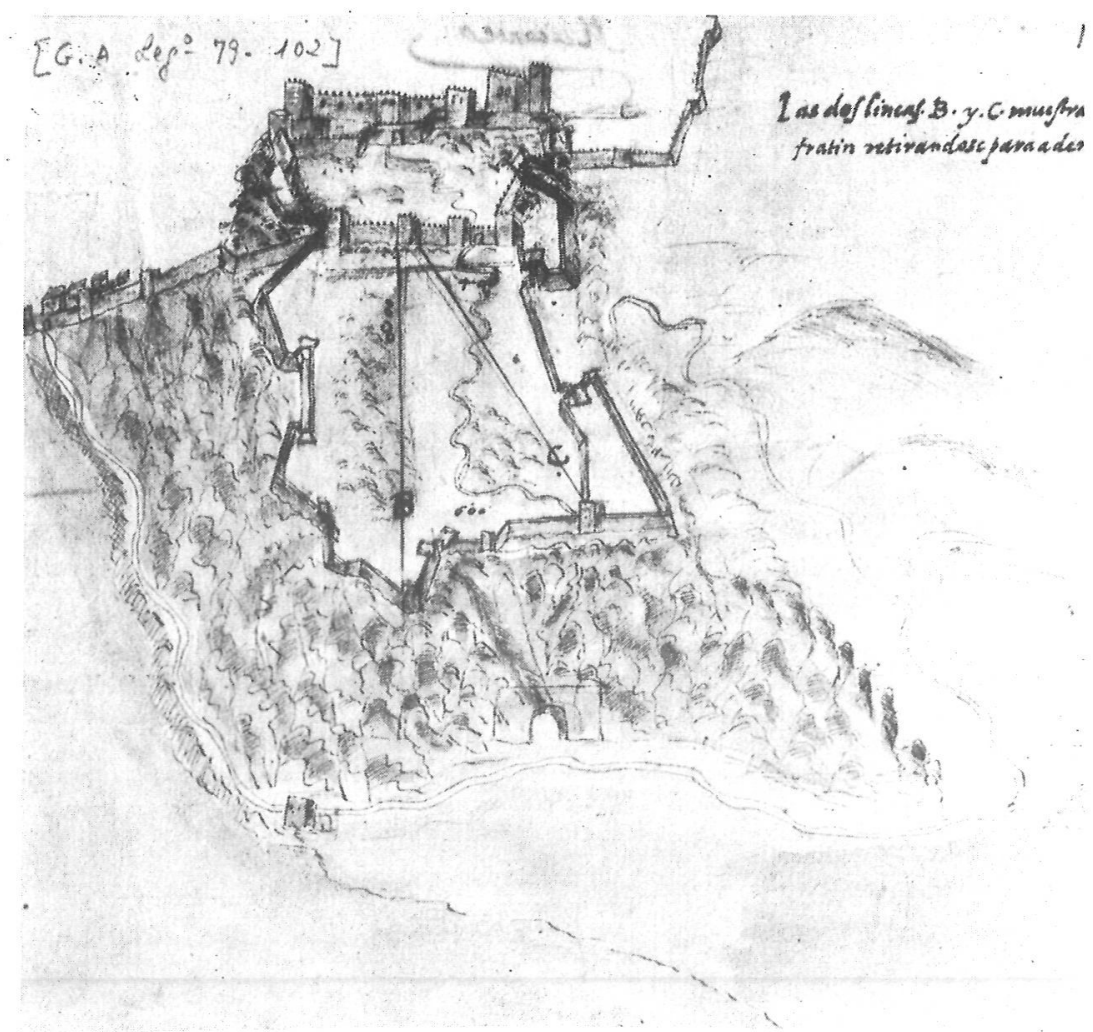


«Por cuanto antecede hemos resuelto despachar la presente carta-priviegio, valedera a perpetuidad, en cuyo tenor convertimos la villa de Alicante en ciudad y la constituimos, creamos y elevamos al rango honorífico de ciudad y la distinguimos y decoramos por nuestra regia autoridad con el honor, grado, título, denominación, elogio y pleno disfrute del rango de ciudad, en la forma y rango que mejor y más util, amplia y latamente pueda entenderse, pensarse y escribirse, para el mejor servicio, cautela, beneficio, seguridad y el más alto bien que pueda redundar en el futuro a favor de la ciudad de Alicante. Por cuanto decretamos y establecemos por el presente edicto nuestro que la que fue hasta la fecha villa de Alicante, deje en adelante de denominarse villa y pase a llamarse y disfrutar en lo sucesivo del nombre y título de ciudad y que así se la denomine en lo sucesivo y así se la intitule y así se la nombre de palabra y por escrito para siempre jamás" (ESTAL, Alicante de villa a ciudad, 1990, $\mathrm{n}^{\circ} 182$, y también la versión castellana que añadimos al final).

Y con el fin de convertir a los vecinos de la recién creada ciudad de Alicante en beneficiarios directos de tan honorífica titulación, dispuso el rey $\mathrm{D}$. Fernando que «La ciudad de Alicante goce a partir de la fecha con todos sus moradores y en plenitud de su derecho de todos aquellos favores, gracias, preeminencias y prelaciones, franquicias, exenciones, libertades y derechos de que vienen ya disfrutando las demás ciudades del reino de Valencia. $Y$ que todos los moradores de la ciudad de Alicante sigan gozando también de los fueros y mercedes reales que han disfrutado hasta la fecha por legitimo derecho, costumbre o tradición inmemorial y viejas costums, constitución o estatuto antiguo o por cualquiera otra causa legal» (ibid.). De suerte que la que hasta ayer fue villa y hoy es ya ciudad por gracia especial del rey, no se vea mermada lo más mínimo en ninguno de los derechos y favores disfrutados hasta el presente, sino antes bien, aquéllos se vean en lo sucesivo ampliamente incrementados y mucho más favorecidos su vecinos. Y así ocurrió en efecto. La nueva titulación de ciudad despertó talmente la conciencia de los vecinos de Alicante, como de haber adquirido un serio compromiso de mayor emulación y más estimulante esfuerzo por alcanzar un mayor desarrollo económico-social, que redundaría a la postre en un despegue urbano mucho más ambicioso y de creciente prosperidad global, cara ya a los primeros albores del siglo XVI. 


\section{TEXTO ORIGINAL LATINO Y VERSION CASTELLANA DEL PRIVILEGIO DE D. FERNANDO EL CATOLICO (Córdoba, 26 de julio de 1490)}

\section{0, julio, 26. Córdoba.}

Diploma original en pergamino del rey Fernando el Católico, II de Aragón y $V$ de Castilla, por el que eleva la Villa de Alicante, en reconocimiento y premio a los numerosos logros alcanzados en la áreas del comercio, la agricultura, la artesania e industria, al rango honorifico de Ciudad, con todos los privilegios y fueros que el referido alto título comporta.

AMA (Arch. Munic. de Alicante), arm. 16, caj. 1, pergamino 33. En su plica interior pueden observarse todavía los orificios de su primitivo sello de plomo, pendiente. Señalamos la interlineación del original.

In dei nomine pateat universis quod Nos Ferdinandus dei gracia Rex Castelle, Aragonum, Legionis, Sicilie, Toleti, Valencie, Gallecie, Maioricarum, Hispalis, Sardinie, Cordube, Corsice, Murcie, Giennis, Algarbii, Algezire et Gibraltaris, Comes Barchinone, / dominus Vizcaye et Moline, Dux Athenarum et Neopatrie, Comes Rossilionis et Ceritanie, Marchio Oristanni, Comesque Gotiani.

Dum Nobis subditas universitates, eas maxime quarum magnitudinem perobtamus pro suis meritis, gradu atque titulo componimus digniori,/ ex hoc quidem gratitudinis nostrum exercentes debitum, etiam regie dignitatis fastigium, uberiori siblimamus preconio.

Hinc est quod provida meditatione in mentis nostre scrinio recognoscentes multa laude memoratuque digna servicia, tam divi recordii predecessoribus nostris regibus / Aragonum et Valencie serenissimis, quam Nobis ac regie domui et Corone Aragonum, multifarie diversisque temporibus, tam domui (?) quam militie affectuose ingentique devotione prestita et impensa per nostram Villam Aliquantis, in littore ac confinibus eiusdem nostri Regni Valencie sitam et positam, / queque Nobis ad presens continuo prestare non cessat, tam per se universaliter quam per unumquenque illius habitatorem in particulari, cum omni integritatis et perfectionis affectu, nullis parcendo dispendiis atque laboribus. Necnon debita videntes discretione quod eadem Villa Aliquantis, nulla deo duce aliena / ope indiget ad bene et politice vincendum. Quinimo omnia in se continet quibus unaqueque civitas constare optime potest. Habet enim Villa ipsa sinum in mari sive mollum insignem. Habet mercatores, agricolas, artifices atque mechanicos. Habet insuper armigeros et alios qui rem-/ publicam debite atque opportune custodire, tueri sufficienter pariter et gubernare possunt. 
Merito quidem et debita racione inducimur ut eiusmodi villam ulteriori atque eminentiori gradu et titulo, quibus hactenus denotata fuit, cum quodam laudis nomine decoremus. His igitur in mentem / nostram obtima adductis consideratione atque per supplicationem Maiestati nostre humiliter inde factam per dilectos et fideles nostros Jacobus Paschasium, militem, et Joannem Torro, nuncios, sindicos et procuratores per dictam villam ad Nos noviter destinatos, iterum cogitatis.

Tenore presentis / charte nostre cunctis futuris temporibus valiture et durature per Nos ac omnes heredes ac successsores nostros quoscumque, gratis, expresse et de certa sciencia ac deliberate et consulte deque nostre regie ac legibus absolute potestatis plenitudine dictam Villam Aliquantis ex nunc in antea / in perpetuum Civitatem creamus, constituimus, ordinamus et facimus atque in Civitatem erigimus et extollimus Civitatisque honore, titulo, gradu, denominatione, gaudio et preconio auctoritate regia insignimus pariter et decoramus. Sicut melius, sanius, utilius, plenius ac latius dici potest, / scribi, intelligi et excogitari ad ipsius Civitatis Aliquantis cautelam, favorem, commodum, securitatem ac bonum etiam sanum et sincerum intellectum. Decernentes, volentes et concedentes atque hoc nostro regio statuentes edicto, quod dicta olim Villa Aliquantis, ammodo non villa sed Civitas / sit perpetuo, sicque vocetur, intituletur, nominetur, scribatur et dicatur. Atque una cum omnibus et singulis illius civibus et etiam sine illis sistare posset ac ceteris habitantibus et habitaturis in ea natis iam et interea nascituris, quod Nos in cives honoratos sublimamus et decoramus, gaudeat, letetur / et fruatur, gaudeantque, letentur et fruantur universis omnibus et singulis honoribus, prelationibus, graciis, favoribus, dignitatibus, preheminenciis, exemptionibus, inmunitatibus, franquitatibus, libertatibus, privilegiis et aliis quibus relique predicti Regni Valencie civitates eorumque cives / et habitatores de jure, foro, constitutione, usu, consuetudine, privilegio, statu, racione aut aliis quomodocumque, ubicumque et qualitercumque gaudent, utuntur et fruuntur atque gaudere, uti et frui possunt et debent.

Serenissimo propterea Joanni Principi Asturiarum et Gerunde primogenito nostro / carissimo, postquam felices dies nostros longevos, deo propicio, in omnibus Regnis et terris nostris inmediato heredi et successori, intentum aperientes nostrum, quo volumus et disponimus atque iniungimus Gerentibus vero vices nostri Generalis Gubernatori / ac Baiulis generalibus in dicto Regno Valencie, tam citra quam ultra Saxonam, Justiciis quoque Baiulis ceterisque demum universis et singulis officialibus et subditis nostris sub nostri dominio et imperio ubilibet tam citra quam ultra mare constitutis et constituendis 
dictorumque officialium locum tenentibus / et seu ab ipsis surrogatis, sive officia regentibus presentibus pariter et futuris districte percipiendo mandamus expresse et de dicta nostri certa sciencia pro prima et secunda jussionibus ac sub ire et indignationis nostre incursu penaque florenorum auri quinque mille, a bonis secus agentis / irremissibiliter exigendorum et nostris inferendorum erariis, quatenus abinde in antea predictam olim villam Aliquantis perpetuo et semper dicant, nominent, intitulent et appellent, sicuti Nos cum presenti dicimus, nominamus, intitulamus et appellamus eamque / cum omnibus et singulis civibus et habitatoribus suis presentibus et futuris, ut dictum est, illis omnibus et singulis, predictis graciis, honoribus, prelacionibus, prerogativis, dignitatibus, favoribus, franquitatibus, inmunitatibus, privilegiis, libertatibus et allis plene atque perpetuis / temporibus, sine aliquo impedimento, obstaculo, contradictione uti, gaudere, frui et letari universaliter et particulariter sinant et faciant, quibus ac prout et quemadmodum alie Civitates eiusdem Valencie Regni, tam de jure, foro, constitutione, usu, consuetudine, statuto, racione / aut aliis quomodocunque et qualitercunque ac cum omni perfectione et integritate utuntur, gaudent et colletantur ac uti, gaudere et colletari possunt et debent, ut prefertur.

Et non contraveniant aut quempiam contravenire permittant quavis racione, occasione vel causa. Si dictus / Serenissimus Princeps paternam benedictionem habet caram nobisque obedire et sua pariter jussa observari gliscit, ceteri autem officiales graciam nostram caram habent, iramque et indignationem nostras preapositas penas verentur non incurrere, cum ita de mente / nostra omnino procedat ac per eos et quemlibet ipsorum compleri et fieri velimus et jubeamus, quibusvis ordinationibus, statutis, mandatis, litteris, rescriptis, constitutionibus, foris, privilegiis, pragmaticis, sanctionibus, capitulis, actis et aliis in oppositum forte factis vel disponentibus / quibus quo ad premissa et pro hac vice dumtaxat ex eiusdem nostre regie potestatis plenitudine expresse derogamus derogatumque esse volumus et censemus, obstantibus nuIlo modo. Declarantes denuo quod per hanc tituli donationem seu Civitatis erectionem privilegiis, tam per nostros / eosdem predecessores quam per Nos concessis, datis et factis universitati et singularibus predictis, ante eiusmodi erectionem, nullo unquam tempore derogari obrogarive possit. Immo illa et quodlibet ipsorum perenniter ac omni futuro tempore in suis persistant atque remaneant robore, effectu / et valore. Supplentes nichilominus ac tollentes de dicta nostri certa sciencia et nostre regie potesstatis plenitudine omnes et quoscunque deffectus, clausulas et solemnitates, ommisiones tam juris quam facti, si qui vel que forsam intervenerint in premissis et seu ea possent quomodolibet obici, argui / seu notari. Quibus non obstantibus volumus et precipimus 
ea omnia et singula debitam et perpetuam obtinere semper atque habere roboris effectus et valoris firmitatem.

In quorum testimonium presentem fieri jussimus nostro comuni sigillo in pendenti munitam.

Datum in civitate / Cordube, die XXVI mensis Julii, anno a nativitate domini Millesimo Quadringentesimo Nonagesimo, Regnorumque nostrorum videlicet Sicilie anno vicesimo tercio, Castelle et Legionis decimo septimo, Aragonum vero et aliorum duodecimo $/$.

Signum (signo real) Ferdinandi dei gracia Regis Castelle, Aragonum, Legionis, Sicilie, Toleti, Valencie, Gallecie, Maioricarum, Hispalis, Sardinie, Cordube, Corsice, Murcie, Giennis, Algarbii, Algezire et Gibraltaris, Comitis Barchinone, Domini Vizcaye et Moline, / Ducis Athenarum et Neopatrie, Comitis Rossilionis et Ceritanie, Marchionis Oristanni Comitisque Goriani, qui predicta concedimus, laudamus et firmamus / (Sigue la firma autógrafa del monarca:) Yo el Rey (y rúbrica) /.

Testes sunt (primera columna): Reverendissimus P(etrus) de Mendoça, Cardinalis Hispanie, Archiepiscopus Toletanus (Columna central:) Spectabiles et nobiles Gaspar Despens, Comes Sclafane. Requesenius de Soler, Gubernator Cathalonie, Camerlengi (Tercera columna:) Magnifici Ludovicus Ferrer, locumtenens Gubernatoris Generalis Valencie, coperius, / et Michael Joannes Gralla, Magister aule (Maestro de Palacio), milites dicti domini Regis consiliarii/.

Sig (signo notarial) num mei Philippi Clementis Serenissimi domini Regis predicti prothonotarii eiusque auctoritate per universam ipsius terram et dominacionem publici notarii, qui predicta de eiusdem domini Regis mandato scribi feci, clausi, cun rasis et correctis in lineis quarta et quinta ubi corrigitur tempori habitatorem in parti ( $y$ rúbrica)l.

Dominus Rex mandavit michi Philippo / Clementis et vidit eam Generalis Thesaurarius et pro-/ thonotarius confecil (Rúbrica).

Vidit eam Generalis thesaurarius / et prothonotarius confeci/ (Margen derecho inferior).

In diversorum Valencie $\mathrm{VI}$ registrata / (Margen inferior derecho del pergamino).

(La plica inferior por último, desplegada, ostenta visibles los orificios del primitivo sello de plomo, colgado - hoy desaparecido-) (3). 


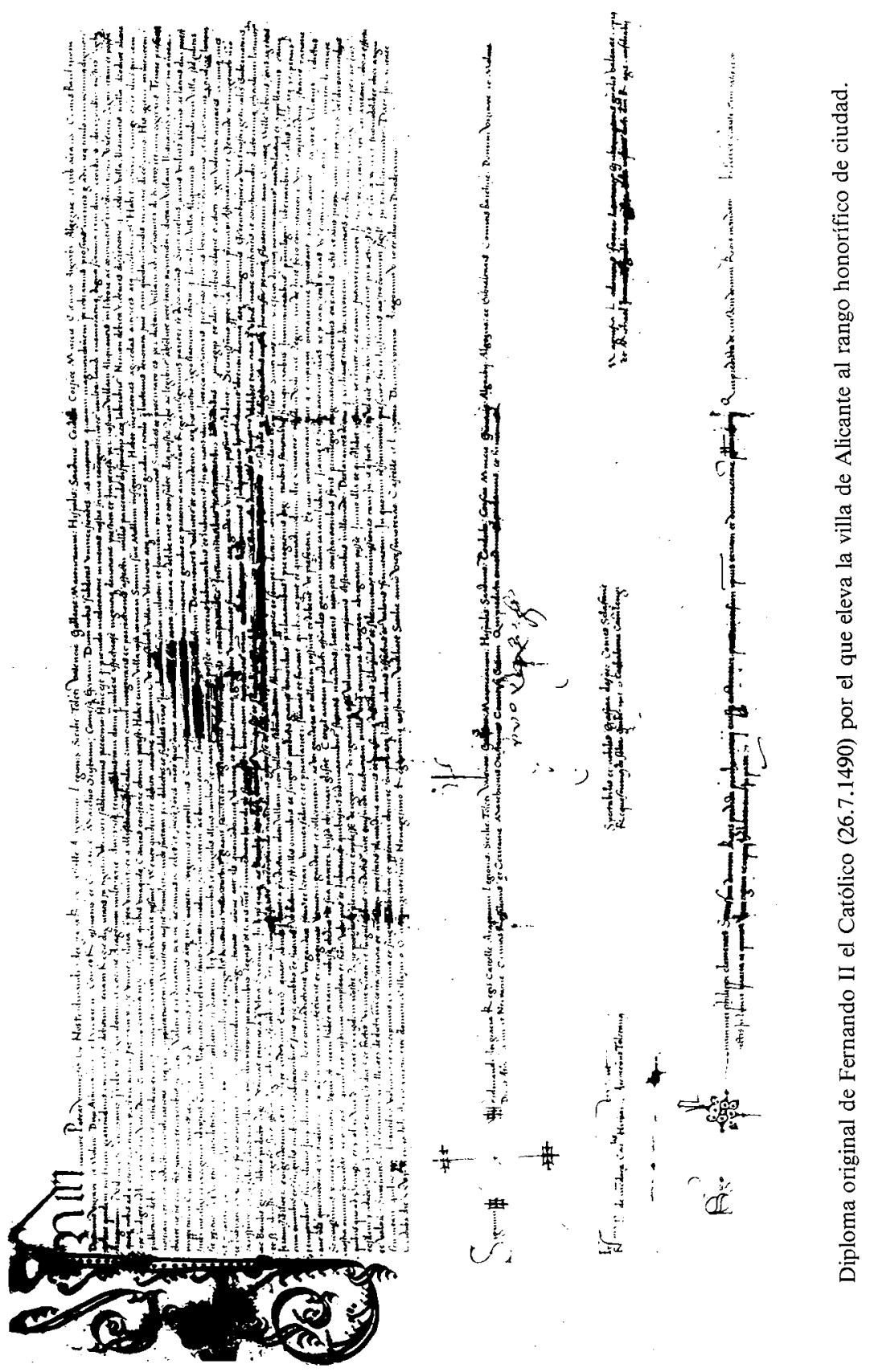


En el nombre de Dios, sea a todos notorio que nos, Fernando, por la gracia de dios rey de Castilla, Aragón, Sicilia, Toledo, Valencia, Galicia, Mallorcas, Sevilla, Cerdeña, Córdoba, Córcega, Murcia, Jaén, Algarbes y Gibraltar, conde de Barcelona, señor de Vizcaya y Molina, duque de Atenas y Neopatria, conde del Rosellón y Cerdaña, marqués de Oristano y conde de Goriano, que al par que deseamos decorar con el grado y título más digno, por la excelsitud de sus méritos, a nuestros pueblos súbditos, los elevamos así mismo, en ejercicio de obligada gratitud regia, al rango de una dignidad superior.

$Y$ he aquí que, considerando los muchos y memorables servicios, dignos de toda alabanza, prestados a nuestros predecesores, de feliz recuerdo, los reyes de Aragón y de Valencia, en tiempos distintos y de muy diversas maneras, y a Nos mismo, a la casa real y a la corona de Aragón, con singular afecto e ingente devoción, por la Villa de Alicante, sita en el litoral y confines meridionales de nuestro Reino de Valencia, y que hasta el presente no cesa de prestarnos tales servicios, tanto por el colectivo universal de su comunidad, como por cada uno de sus vecinos en particular, con el afecto más íntegro y perfecto y sin renunciar a ningún sacrificio ni trabajos; y considerando además atentamente que dicha Villa de Alicante providencialmente no necesita de ayuda alguna foranea para valerse bien y prosperar políticamente; y teniendo en cuenta sobre todo que posee todo aquello que una ciudad puede tener óptimamente; pues tiene esta Villa una ensenada excelente y un muelle insigne; tiene también mercaderes, agricultores, artesanos e industriales; y dispone además de hombres de armas y gentes que pueden guardarla con seguridad, y defenderla a ultranza y gobernarla bien; es por todo ello por lo que justamente y con sobrada razón nos veamos impelidos a decorar a dicha Villa con un grado y título más eminente y de mayor renombre del que ha gozado hasta la fecha.

Ante la consideración de tan singulares méritos, presentados a nuestra Majestad humildemente por los síndicos, mensajeros y procuradores de dicha Villa, Jaime Pascasio, caballero, y Juan Torro, destinados a nuestra presencia con tal cometido, hemos resuelto emanar la presente Carta-Privilegio valedera a perpetuidad, por todos los tiempos, y duradera para Nos y todos nuestros sucesores, por cuyo tenor, de forma espontanea, expresa, con co: nocimiento pleno de causa, deliberada y voluntariamente, y al amparo absoluto de nuestras leyes y plenitud de nuestra regia potestad, convertimos a di- 
cha Villa de Alicante en Ciudad a perpetuidad y la constituimos, creamos y elevamos a tal rango honorífico de Ciudad y la decoramos y distinguimos por nuestra autoridad real con el honor, grado, título, denominación, elogio y disfrute del rango de ciudad, en la forma y grado que mejor y más útil y amplia y latamente pueda entenderse, pensarse o escribirse, para el mejor servicio, cautela, beneficio, seguridad y el mayor y más alto bien de la Ciudad de Alicante. Por cuanto decretamos, concedemos, deseamos y establecemos por este edicto real, que la que hasta ahora fue Villa de Alicante, en adelante deje de ser villa al convertirse en Ciudad para siempre y así se la llame, denomine e intitule, y asi se la mericione, diga y nombre de palabra y por escrito. $Y$ decretamos así mismo que disfrute de tal nombre junto con todos y cada uno de sus ciudadanos e incluso sin ellos, e igualmente con sus moradores presentes y futuros, a quienes por el presente decreto elevamos al rango honorifico de ciudadanos honrados, estableciendo que tanto la Ciudad de Alicante, como sus ciudadanos gocen plenamente, se beneficien y disfruten de lleno de todos y cada uno de los honores, prelaciones, gracias, favores, dignidades, preeminencias, exenciones, inmunidades, franquicias, libertades, privilegios y de cuantas cosas más las restantes ciudades del Reino de Valencia, así como sus ciudadanos y moradores gozan, usan y disfrutan por derecho, costumbre, fuero, constitución, uso, privilegio, estatuto o cualquier otra razón o motivo, debiendo por ello poder disfrutar siempre, doquier y de todas maneras sus vecinos de los referidos derechos, usos, costumbres y fueros.

Ordenamos además, por expreso y solemne mandato real, a nuestro carísimo primogénito, el Serenísimo Juan, Príncipe de Asturias y Gerona, que, cuando dios mediante Nos suceda en todos nuestros reinos y tierras, respete plenamente nuestro deseo e intención manifiesta, ordenando a su vez y disponiendo, al amparo de la bendición paternal al par que imponemos por la presente Carta-Privilegio y ordenamos también de igual modo a los lugartenientes (Gerentes-vices) de nuestro Gobernador General, así como a los Bayles Generales, en el susodicho reino de Valencia, de uno y de otro lado de Jijona, y a los Justicias, Bayles y demás Oficiales locales, como también a los súbditos nuestros que se encuentren tanto a éste como al otro lado del mar bajo nuestra soberanía real, y a los lugartenientes de nuetros oficiales susodichos y a cuantos ejerzan en su nombre tales oficios públicos, que, bajo la amenaza de incurrir en nuestra ira e indignación regia, y la pena monetaria de adeudar al erario público la suma de 5.000 florines de oro, que de aquí en adelante tengan y denominen por siempre Ciudad a la que fuera hasta el presente la Villa de Alicante, y así la llamen, nombren, denominen e intitulen, como es nuestro deseo y voluntad, y por el presente decreto real así Nos 
la llamamos, intitulamos y decimos y, como tal, asi queremos que disfrute en adelante a perpetiudad de tal predicamento.

Disponemos igualmente que todos sus vecinos, así presentes como futuros, gocen juntos con la Ciudad de Alicante de todos y cada uno de los honores, gracias, prelaciones, perrogativas, dignidades, favores, franquicias, inmunidades, privilegios, libertades y cuantas cosas más quedan referidas, de modo pleno y a perpetuidad, para siempre, y puedan disfrutar todos y cada uno de los fueros susudichos, sin el menor impedimento, obstáculo o contradicción, al igual que otras ciudades del Reino de Valencia disfrutan de los mismos por derecho, constitución, fuero, uso, costumbre, estatuto o cualquier otra razón, y pueden y deben gozar de todas formas y cualquier modo y toda perfección, integridad y plenitud del referido título y demás beneficios apuntados, pertinentes al mismo. Disposición que a nadie le es permitido contravenir, ni se tolere a nadie hacerlo, por cualquier razón o motivo.

Y si el Serenísimo Príncipe, antes mencionado, descuidase nuestra cara paternal bendición y nos desobedeciese, no manteniendo las disposiciones que proceden, y así mismo los demás oficiales públicos hicieren otro tanto, sin temor a incurrir en nuestra ira e indignación real, ni a las penas apuntadas anteriormente, como nuestra voluntad firme y decidida sea la de cumplir y hacer cumplir absolutamente cuanto hemos dispuesto por el real decreto, desde ahora y por esta sola vez, en ejercicio de la plenitud de nuestra potestad real, derogamos y declaramos expresamente derogado cualquier acto en contra de cuanto hemos dispuesto, sin que obste nada en contrario absolutamente, declarando por ello nulos plenamente cuantos actos, ordenaciones, estatutos, mandatos, cartas, rescriptos, constituciones, fueros, privilegios, sanciones, pragmáticas, capítulos y demás actos que puedan producirse en contra de nuestra disposición real antedicha.

Declaramos por todo ello una vez más y de nuevo que el título de Ciudad que acabamos de otorgar a la villa de Alicante por nuestro real decreto, no podrá jamás ser derogado ni obregado por ningún privilegio concedido a dicha Ciudad por nuestros predecesores o Nos mismo, con anterioridad a la fecha de ser elevada al rango de Ciudad. Antes bien declaramos que todos los privilegios reales de que disfruta y ha disfrutado hasta la fecha sigan vigentes en su plenitud, valor y firmeza por siempre jamás en beneficio de la misma.

Suplimos y retiramos así mismo, en pleno conocimiento de causa y ejercicio de la plenitud de nuestra real potestad, todos aquellos defectos de for- 
ma, claúsulas y solemnidades, omisiones así de derecho como de hecho, si alguno de ellos se hubiese dado y pudiera aducirse como objeción u obstáculo a la ejecución de nuestro decreto real susodicho. Por lo que, no obstando nada en contra de lo dicho, ordenamos y queremos que todo cuanto hemos dispuesto al respecto, total y singularmente, mantenga por siempre la debida firmeza y consolidación del efecto deseado a perpetuidad.

En testimonio de lo cual hicimos confeccionar la presente Carta-Privilegio, corroborada con nuestro real sello de plomo habitual, pendiente.

Dada en la ciudad de Córdoba, a veintiseis de julio, del año del nacimiento de nuestro Señor mil cuatrocientos noventa, y de nuestros reinos a saber: el de Sicilia, el año veintitres, el de Castilla y León, el diecisiete, y del de Aragón y otros, el doce.

Signo real de Fernando, por la gracia de dios rey de Castilla, Aragón, León, Sicilia, Toledo, Valencia, Galicia, Małorcas, Sevilla, Cerdeña, Córdoba, Córcega, Murcia, Jaén, Algarbes, Algeciras y Gibraltar, conde de Barcelona, duque de Atenas y Neopatria, conde del Rosellón y Cerdaña, marqués de Oristano y conde de Goriano, quien sancionamos, concedemos y suscribimos cuanto precede.

Yo el Rey (y sigue la rúbrica real).

Firman como testigos: el Reverendísimo Pedro de Mendoza, cardenal de España y arzobispo de Toledo; los ilustres y nobles Gaspar Despens, conde de Sclafano; Requesens de Soler, Gobernador de Cataluña, Camarlengo. Los magníficos Luis Ferrer, Lugarteniente del Gobernador General de Valencia, copero, y Miguel Juan Gralla, maestro de Palacio, caballeros y consejeros del dicho Señor Rey.

Signo notarial de mí, Felipe Clemente, protonotario del Serenísimo Señor Rey predicho y por autoridad suya notario público en todos sus dominios, quien por mandato del dicho Señor Rey hice escribir cuanto antecede y cerrar, con el raspado y corrección de las palabras tempori habitatorem in parti en las lineas cuarta y quinta (Sigue la rúbrica de este Notario).

El Señor Rey me ordenó a mí, Felipe Clemente, confeccionar esta CartaPrivilegio real y le dió su Visto Bueno el Tesorero General y yo, el protonotario la hice escribir (sigue su rúbrica).

Está registrada en la Sección Diversorum Valencie, volumen VI (Escrito al margen inferior derecho). 
(La plica inferior, desplegada, ostenta aún los orificios del primitivo sello de plomo, colgado, hoy desaparecido).

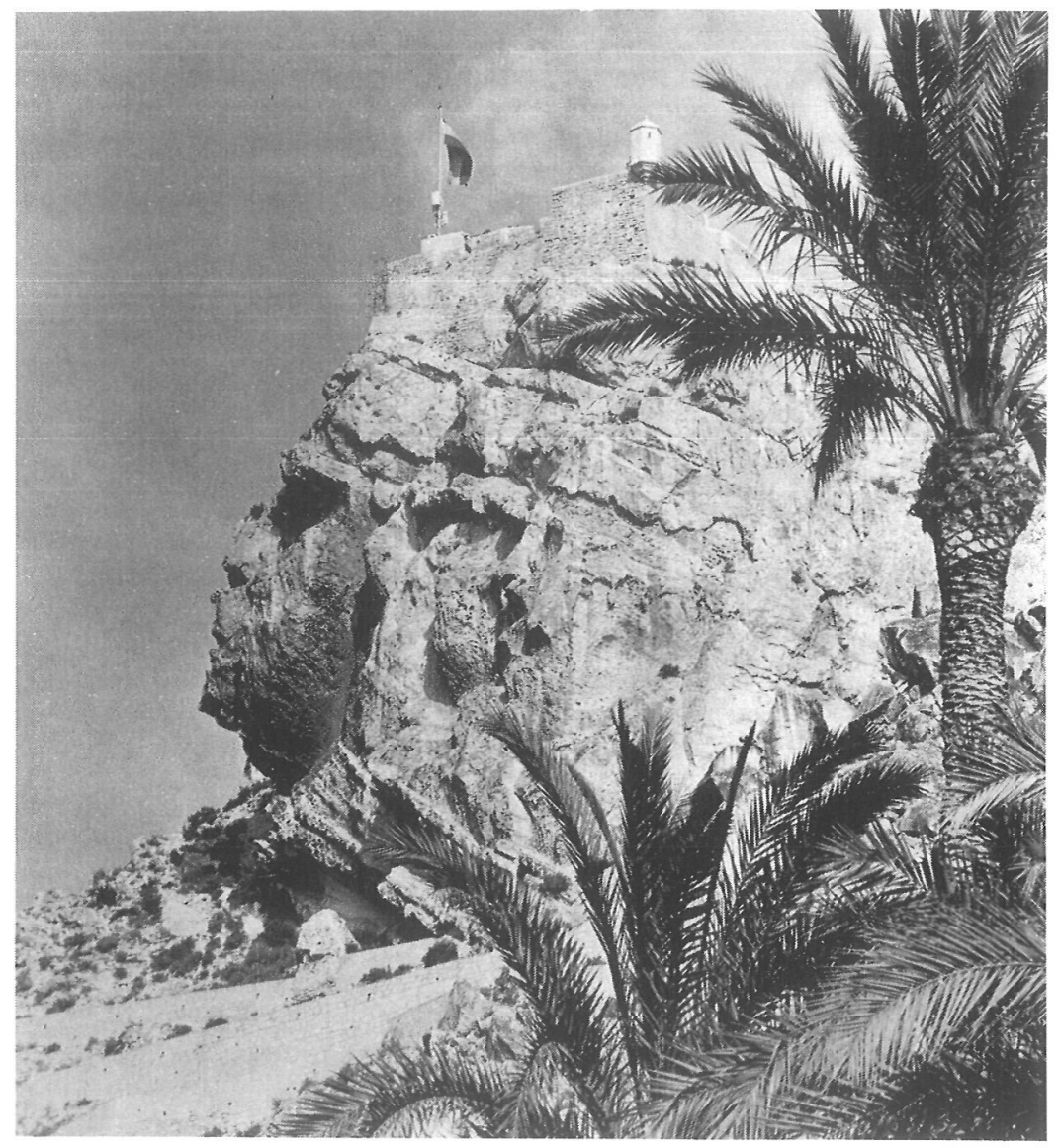

Vista parcial del Castillo de Alicante. 
(1) Transcribimos el texto latino por primera vez del manuscrito original del pergamino descrito, conservado en el Archivo Municipal de Alicante, con la signatura ya apuntada.

(2) Para los periodos anotados de la Historia de Alicante medieval, v. ESTAL, J.M. del. Documentos inéditos de Alfonso el Sabio, Alicante, 1984; Id. El reino de Murcia bajo Aragón, Alicante, 1985; Id. Historia de la provincia de Alicante, 1986, pp. 171-286; Id. Alicante de villa a ciudad, Alicante, 1990, passim.

(3) Hay copia de este diploma de Fernado II el Católico en el ARV, Reg. VI In Diversorum, fol. CCIIII.

AMA (Arch. Munic. de Alicante), Arm. 1, lib. 3: Privilegios y Provisiones Reales de la Ciudad de Alicante, fols. 257r-258v.

De este Cartulario alicantino tomó D. Vicente Martínez Morellá, Privilegios y Provisiones de Fernando el Católico a Alicante, Alicante, 1951, en el n. ${ }^{\circ} 4$, págs.24-28, interpretando incorrectamente algunos términos del texto original. 